concentric flames now employed. The dome is of rolled copper, the plinth or base of massive cast-iron lined with iron sheets. The cost of such a lantern is about $£ 1700$. 'The lantern of recent lightships has been treated in the same way, having regard to its lightness, mobility, and smaller dimensions. The diameter has been extended to 8 feet, the height of plate-glass to $4 \mathrm{fcet}$, the cyilindrical form substituted for every other.

It does not seem possible to construct lighthouse towers and lanterns of better designs and materials than those which have been described. An important amplification of the dimensions may, however, be resorted to in the future to meet the increasing radii of the lenticular apparatus, and the increasing size and height of the central flames. This is on the assumption that electricity does not displace petroleum and gas as illuminants. It may be counted as an additional clain of the arc to be the light of the future that it requires no apparatus larger than Fresnel's first order of 920 millimetres focal dis. tance, and that therefore no lantern exceeding it feet in diameter with 10 feet of glazing, and no tower with a diameter of platform greater than 23 feet, would certainly be needed. The merits and prospects of the rival illuminants will be discussed in a subsequent article.

\section{(To be continued.)}

\title{
CONDENSATION OF GASES.
}

A MONG the numerous subjects which have engrossed the attention of the knowledge-seekers of the present century, probably none have surpassed in fascination and in the wealth of results which have followed persistent effort the question of the possibility of liquefying those gases which for ages had been considered permanent. Immediately after that epoch-making period in chemistry and physics, when Faraday, followin in the footsteps of Northmore who in 1806 had succeeded in liquefying chlorine, announced to the world the fruitful results of his experiments upon the liquefaction of gaseous sulphurous, carbonic, and hydrochloric acids, nitrous oxide, cyanogen, and ammonia, came a long interval, during which all attempts to induce hydrogen, oxygen, nitric oxide, marsh gas, and carbon monoxide to take up the liquid state yielded little more than negative results, and the subject appeared almost without hope. When one looks back to the end of the year 1877 and remembers the thrill of excitement which ran through the civilized world when the double announcement was made by the French Academicians that oxygen had been independently liquefied by Cailletet and Pictet, and then, in the mind's eye, reverts to the long years of trial and experiment during which these and other workers were slowly but surely building up future success on present failure, one cannot but be cheered by the thought that patient work inevitably brings its own reward. The fundamental principle upon which both based their experiments was, that the gases must be simultaneously exposed to very high pressures and to temperatures lower than their critical points. Pictet, whose apparatus was a triumph of mechanical skill, evolved his gas to be liquefied from a strong wrought-iron cylinder, from whence it passed into a closed copper tube surrounded by a cold bath of rapidly evaporating liquefied carbon dioxide, which reduced the temperature to $-130^{\circ} \mathrm{C}$. Cailletet arrived at the same end by using a hydraulic press to compress his gas, but instead of using a very cold bath he caused the gas to effect its own reduction of temperature by suddenly releasing the pressure, causing rapid evaporation, and hence such a considerable cooling that the gas condensed in drops of liquid. Pictet, on January 10,1878 , further succeeded in crowning his results by liquefying hydrogen at a pressure of 650 atmospheres and at a temperature of

- I $40^{\circ}$, and finally, on relcasing the pressure, by actually solidifying the hydrogen, which fell "like so many drops of steel "upon the ground.

But now came the question of the possibility of producing still lower temperatures, so as to effect the same result at correspondingly lower pressures, and so successful have efforts in this direction been that the more permanent gases have at last been liquefied at pressures nearly approaching atmospheric, and retained in the liquid form under even less than atmospheric pressure. This is a great leap in advance, for it not only enables us to determine the boiling-points of the liquefied gases at ordinary pressure, but also to determine their densities in strictly comparable numbers. This happy consummation we mainly owe to the untiring efforts of Dr. K. Olszewski, whose latest results have just been given to the world, and a short description of whose work will probably be of general interest

The most critical portion of any apparatus for such a purpose is of necessity the glass tube in which the liquefaction is to occur, the capacity of which for withstanding rapid changes of both temperature and pressure is put to the severest test. Olszewski paid particular attention to the preparation of his tube, heating it for some time almost to redness in an iron tube packed with calcined magnesia, and allowing it to cool slowly beneath a thick layer of hot ashes, thereby obtaining a tube in which more than a hundred experiments were performed without a single explosion. The open end of this tube, $a$, was attached to a brass flange, $b$, the upper part of which was furnished with two openings, one for the hydrogen thermometer, whose bulb reached to the bottom of $a$, the other uniting the tube $a$ with a branched copper tube $e$, by means of which connexion could be made at pleasure with (1) the manometer $f$, for use with pressures smaller than atmospheric, (2) an air-manometer, $g$, for use with higher presiures, (3) a large air-pump for reducing the pressure upon the liquefied gas, (4) an aspirator, $r$, used as afterwards described in the density determinations, and $(5)$ an iron Natterer cylinder, $i$, in which the gas to be liquefied was stored up under a pressure of $60-80$ atmospheres. A caoutchouc stopper, $k$, held the liquefaction tube within a system of glass cylinders designed for the reception of liquid ethylene, which was used to effect the reduction of temperature, and for preserving the same from the warming influence of the surrounding air. The four vessels were held within each other without touching by pieces of cork and felt rings, so that the ethylene was separated from the surrounding air by badly conducting layers of air, and the evaporated ethyl. enc, passing in the direction of the arrows between the walls, still further counteracted the influence of radiation from warmer surroundings. In the outer cylinder were placed a few picces of chloride of calcium in order to dry the air and prevent the deposition of hoar frost. The liquid ethylene was supplied from a second Natterer cylinder, $l$, fitted with a siphon arrangement and placed in a mixture of ice and salt; on the way to its receptacle the ethylene passed through a spiral copper tube surrounded by a freering mixture of solid carbon dioxide and ether contained in a double-walled vessel, $m$. On connecting the vessel with the air-pump and reducing the pressure, the temperature of this freezing mixture sank to $-100^{\circ}$, and 150 r.c. of liquid ethylene were obtained, which remained perfectly quiet for hours under atmo. spheric pressure. The glass tube $n$ was then connected with the air-pump, by means of which the pressure was reduced until the ethylene began to boil; here however a difficulty, for a long time insurmountable, presented itself; for it was found that inequalities of temperature in the ethylene column caused violent disturbances, and the liquid rapidly disappeared out of the vessel. A simple expedient, however, that of forcing a regulated stream of dry air through the ethylene, was eventually hit upon and 
found to work admirably, keeping the whole column in constant agitation and at a measurable temperature. The pressure over the ethylene was maintained by use of the air-pump at about to millimetres of mercury.

By this means such a diminution of temperature was effected that all gases, with the exception of hydrogen, could be liquefied at pressures not exceeding 40 atmospheres. As soon as the manometer of the air-pump indicated to mm., the valves $f$ and $h$ were closed, and $i$ of the Natterer cylinder opened, admitting the gas to be liquefied into the tube $a$ at $40-60$ atmospheres pressure, as incticated by the manometer $g$, when a considerable quantity of the liquefied gas was readily obtained. And now Glszewski elaborated a most ingenious device, by means of which the liquid could for some time be retained as such on releasing the pressure, and even-which is almost incredible, and a striking example of the truth of the adage "fact is stranger than fiction"-in vacuo. The addition to the apparatus consisted of the introduction in the liquefaction tube of a second thinner-walled tube, about half the length of the former and of smaller diameter, so that, when in position, the distance of its walls from those of $a$ was about I millimetre. On performing the experiment as before, the liquid first collected only in this interspace, after a short time also in the inner tube, thus exhibiting two meniscuses; eventually the liquid in the interspace flowed over into the inner tube, and finally the levels equalized at its edge. The liquid was now gradually freed from pressure by shutting off the Natterer cylinder and its manometer and opening the valve $h$, and consequently reduced in temperature still further by the evaporation produced, hence the liquefied ethylene became relatively warmer and caused the liquefied gas contained in the interspace to evaporate

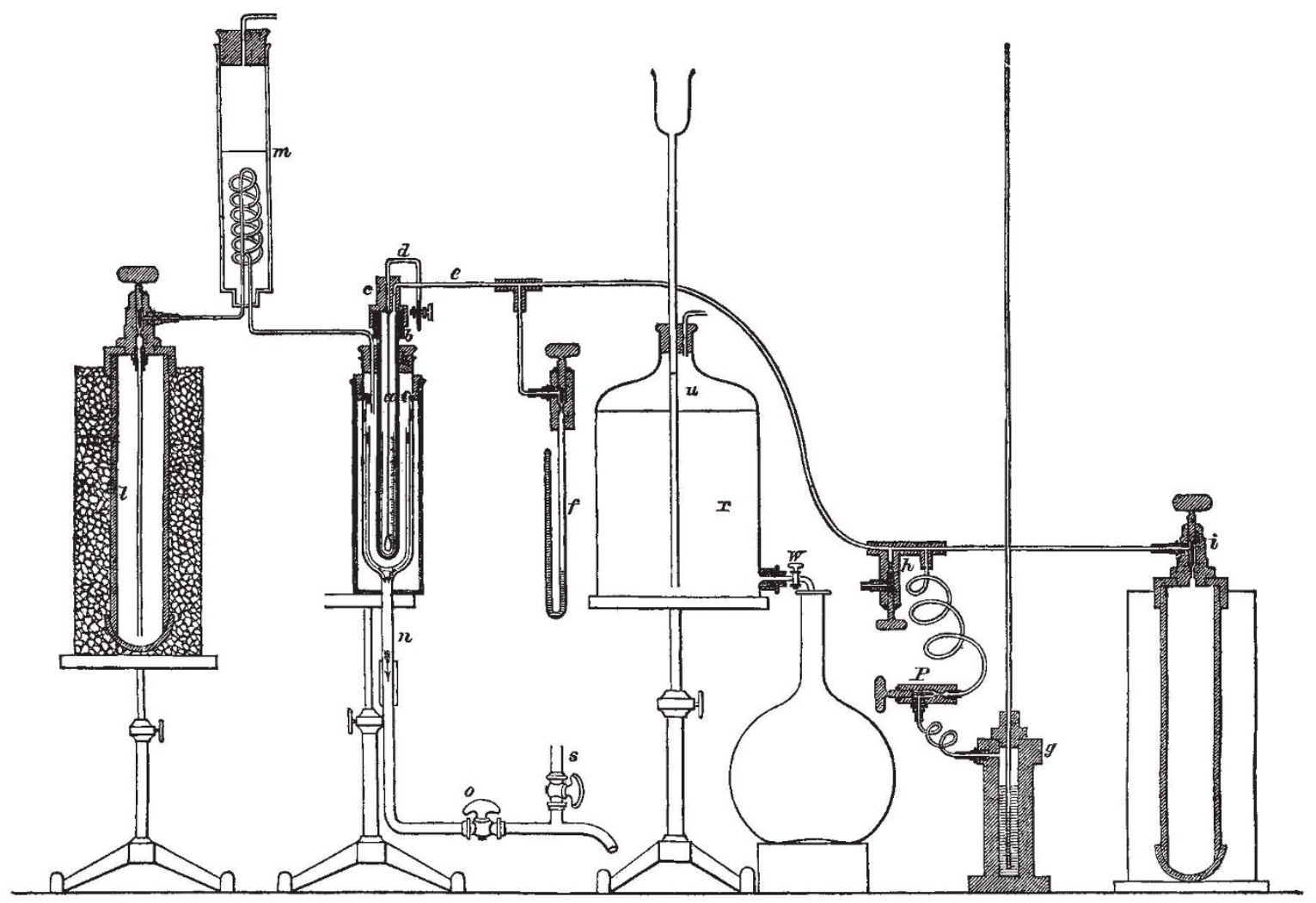

entirely away, leaving a badly conducting layer of gas, whose eminent isolating action was found sufficient to keep the remainder in the inner tube in the liquid state at normal atmospheric pressure. One step further: on closing the stopcock $o$, and connecting $h$ with $s$ by means of lead and caoutchouc tubing, communication was effected between the liquefaction tube and the air-pump, and, owing to the before-mentioned action of the layer of gas, a notable quantity of the liquefied gas still remained at pressures below 100 millimetres of mercury, as shown by the manometer $f$. The temperature of liquefied oxygen under these circumstances sank to $-198^{\circ} \mathrm{C}$., that of air to $-205^{\circ}$, and that of nitrogen to $-213^{\circ}$.

In his latest work Olszewski used two such little isolating tubes, and was enabled to reach in case of oxygen $-2 \mathrm{II}^{\circ}$; at $-207^{\circ}$ and roo millimetres pressure, carbon monoxide solidified, as did aiso nitrogen at -214 and 60 millimetres.

By lowering the pressure over the solid nitrogen to 4 $\mathrm{mm}$., Olszewski succeeded in penetrating the dark region approaching absolute zero as far as $-225^{\circ} \mathrm{C}$. It will be remembered that Pictet found a pressure of $65^{\circ}$ atmospheres necessary at $-140^{\circ}$ to liquefy hydrogen, but by combining the above apparatus with one similar to Cailletet's, so that the gas could be subjected to 190 atmospheres pressure at $-213^{\circ}$, Olszewski has effected the same result, which was also independently obtained by use of liquefied nitrogen boiling in vacuo (Compt. rend. xcviii. 91 3, I 884).

The chief importance of these experiments lies in the fact that it now becomes possible to determine several of the physical constants of liquefied gases at ordinary 
pressure, and a short description of how this has been done may not be uninteresting.

In order to determine the boiling-points, about 15 cubic centimetres of the liquid were obtained as above, gently freed from pressure, and communication with the air established by opening the valve $h$. Marsh gas, nitric oxide, and oxygen behaved under these circumstances perfectly quietly, evaporating only from the surface, necessitating shaking of the apparatus to prevent superheating; while in the case of carbon monoxide and nitrogen the evaporation proceeded with gentle ebullition It required 5 to 15 minutes for the liquid to escape completely out of the apparatus, affording ample time to take the boiling-point with a hydrogen thermometer. A list of the boiling-points obtained is given in the table. It is satisfactory that Wroblewski has completely confirmed the accuracy of Olszewski's temperatures by thermoelectric measurements, and he asserts that a hydrogen thermometer affords correct indications as far as $-193^{\circ}$ but the latter gentleman proves that the error must be very small, as all the boiling-points are above $-220^{\circ}$, the critical ternperature of hydrogen, and he shows that oxygen and nitrogen thermonneters are mot influenced by an error exceeding $2^{\circ}$ even at several degroes below their critical points. From an inspection of the critical points given in the table we can at once see why the earliest attempts to liquefy these gases so utterly failed, for no amount of pressure would liquefy nitrogen for instance, unless its temperature could be at the same time reduced to $-146^{\circ}$, a temperature not procurable by the means known to the earlier experimenters.

For the purpose of the density-determinations the inner tube within the liquefaction tube was calibrated, the thermometer removed, and the hole in the stopper closed with glass rod and sealing-wax. About $55 \mathrm{C.c}$ of the liquefied gas were obtained as before, freed gradually from pressure, and, as soon as all the liquid in the interspace had evaporated, the height of the liquid column left under atmospheric pressure was read off At the moment of reading off the valve $h$ was connected by a caoutchouc tube with the aspirator $r$, and when the gas was completely volatilized, water was run out until the levels in the tube and respirator were again equalized. The volune of water received in the meaguring-flask was of course equal to that of the gas formed by evaporation of the known volume of liquid, and, after applying certain corrections dependent upon the nature of the apparatus, was reduced to $0^{\circ}$ and $760 \mathrm{~mm}$. As the pressures under which the densities of marsh gas, oxygen, and nitrogen were determined were nearly identical, the numbers obtained are strictly comparable.

$\begin{array}{lcccl} & \begin{array}{c}\text { Boiling- } \\ \text { p.int. } \\ 0 \text { C. }\end{array} & \begin{array}{c}\text { Melting- } \\ \text { point. }\end{array} & \begin{array}{c}\text { Critical } \\ \text { p.int. } \\ 0\end{array} & \text { Density. } \\ \text { Marsh gas } & -164 & & & 0.415 \text { at }-164^{\circ} \text { and } 736 \\ \text { Oxygen } & -181.4 & & -118.8 & 1.124 \text { at }-181^{\circ} 4 \text { and } 743 \\ \text { Nitrogen } & -194.4 & -214 & -146 & 0.885 \text { at }-194.4 \text { and } 741 \\ \text { Carbon } & -190 & -207 & -139.5 & \\ \text { monoxide } & -190 & & \end{array}$

It is a subject for sincere congratulation that these dangerous experiments should have been so far free from accident, but this immunity was not to last ad infinitum, for, just as the last experiment with nitrogen was in progress, the liquefaction tube suddenly flew to pieces and so deranged the apparatus that the densities of carbon monoxide and nitric oxide could not be determined.

These researches, taken in conjunction with those of Victor Meyer on the dissociation of the molecule of iodine, and of Lockyer, Liveing and Dewar, and other workers on the effect of high temperature generally in simplifying the structure of molecules, have assisted, and will in the future assist us still more, in arriving at much more accurate views respecting the ultimate structure of matter itself. On the assumption that the molecule of iodine consists of two atoms, which, according to the view now becoming more and more accepted by thinkers on this subject, may themselves consist of aggregations of a still simpler substance-aggregations which, at temperatures obtainable in the laboratory, we have not been able to break up-the classical experiments of Victor Meyer have shown that at a temperature of about $1500^{\circ} \mathrm{C}$. the molecules are dissociated into single atoms, that is to say, the intensity of the heat-vibrations is so great that the attraction between the two atoms in the molecule is overcome, and they are torn asunder. At still higher temperatures there is a possibility that the atom itself could be resolved into something simpler still.

Reasoning on the same lines, there is great probability that even hydrogen, oxygen, and other more permanent gases could, by a sufficiently high temperature, be resolved first into single atoms and then into something simpler still. Now, taking the opposite extreme, on reducing the temperature sufficienthy to liquefy and even to solidify these gases, we ought to find that as the atoms in the molecule are allowed to approach more closely, and consequently to attract each other more strongly (according to the law of inverse squares), the difficulty of breaking up the molecule into its constituent atoms is more and more increased. This, in the case of liquefied oxygen, has been directly proved to be the case by a series of very beautiful experiments performed by Prof. Dewar, who has shown that liquefied oxygen at $-160^{\circ} \mathrm{C}$. has not the slightest chemical action upon, among other substances, the alkali metals and phosphorus, which in ordinary air or oxygen are rapidly converted to oxides. Chemical action, if such there had been, would have shown that the force of the attraction of atoms of phosphorus or potassium for those of oxygen exceeded that of the atoms of oxygen for each other ; but the result proved that at this low temperature the force (whatever force may mean) exerted between the atoms of the molecule of oxygen was greater than that between the atoms of potassium and oxygen. What the possibilities are as we approach absolute zero form an interesting subject for the "scientific use of the imagination," but, reasoning from analogous phenomena of polymerization, of which organic chemistry furnishes so many examples, and from the antilogous effect of high temperature, we have some reason to suppose that the condensation will continue until molecules more complex than those consisting of the ordinary two atoms are built up. However this may be, the main result of these important experiments has certainly been to show in the clearest possible light how completely the state of matter depends upon the temperature under which it exists.

\section{A. E. Tutron.}

\section{A RECENT JAPANESE EARTHQUAKE.}

PROFESSOR SEKIYA, of the Imperial University, Tokio, has lately sent to this country a remarkably interesting and complete record of earthquake motion obtained by him during a severe shock which occurred at 6.52 p.m. on January 15 of this year. The most important portion of the record is shown in Fig. 1 , reduced to a little more than one-thind of the original size. The motion is recorded (by means of the writer's horizontal pendulum and vertical motion seismographs) in three rectangular components - two horizontal and one vertical-on a plate of smoked glass which is caused to revolve uniformly by clockwork. The plate is started by an electric seismoscope at the beginning of the disturbance, and for one or two seconds its motion is consequently slower than the uniform rate it afterwards attains. On this occasion the plate made one revolution in 126 seconds, and the hori- 